\title{
Changes in Serum Cytokine Levels in Active Tuberculosis With Treatment
}

\author{
Figen Deveci, ${ }^{1}$ H. Handan Akbulut, ${ }^{2}$ Teyfik Turgut, ${ }^{1}$ and M. Hamdi Muz ${ }^{1}$ \\ ${ }^{1}$ Department of Chest Diseases, Firat Medical Center, Faculty of Medicine, Firat University, 23119 Elazig, Turkey \\ ${ }^{2}$ Department of Immunology, Faculty of Medicine, Firat University, 23119 Elazig, Turkey
}

Received 9 May 2005; accepted 1 July 2005

\begin{abstract}
It has been reported that IFN- $\gamma$, TNF- $\alpha$, and IL-12 stimulate, and that IL-10, TGF- $\beta$, and IL- 4 suppress the protective immune response against tuberculosis. We aim to evaluate changes in the serum levels of pro and antiinflammatory cytokines in active pulmonary tuberculosis (APTB) and the possible effects of treatment on these changes. Serum IL-12p40, IL-4, IL-10, TNF- $\alpha$, IFN$\gamma$, and TGF- $\beta 1$ levels were determined in 20 APTB cases (group 1) before and 2, 4, and 6 months after therapy. The same parameters were also determined in 9 inactive pulmonary tuberculosis (IPTB) cases (group 2) and 9 healthy controls (HC, group 3). Before treatment, the mean serum IFN- $\gamma$, TNF- $\alpha$, and IL-10 levels in group 1 were statistically higher than those in group $2(P=.001$, $P=.024, P=.016$, resp) or group $3(P=.003, P=.002, P=.011$, resp). The levels in group 1 decreased significantly after treatment $(P=.001$ for IFN- $\gamma, P=.004$ for TNF- $\alpha, P=.000$ for IL-10). The serum levels of IL-12p40 were significantly higher in group 1 than in group $3(P=.012)$ and decreased insignificantly after treatment. There was no difference in serum IL-4 and TGF- $\beta 1$ levels among the groups $(P>.05)$. Because the serum IL-12p40, IL-10, TNF- $\alpha$, and IFN- $\gamma$ levels were high in APTB, we believe that these cytokines have important roles in the immune response to Mycobacterium tuberculosis ( $M$ tuberculosis). These parameters could be used in follow-up as indicators of the success of APTB therapy.
\end{abstract}

\section{INTRODUCTION}

Mycobacterium tuberculosis ( $M$ tuberculosis) is one of the most widespread pathogens; it is estimated that roughly one third of the world's population is infected with the bacillus and approximately $8-10$ million people become infected every year. It is responsible for 8-12 million cases of active tuberculosis each year, and 3 million deaths $[1,2,3]$. In Turkey, the incidence of disease was $31.5 / 100000$ in 1997 and mortality rate was 2.1/100 000 in 1996 [4].

The interaction of $\mathrm{T}$ cells with infected macrophages is central to protective immunity against $M$ tuberculosis and depends on the interplay of cytokines produced by each cell [5]. TNF- $\alpha$, IL-12, and IFN- $\gamma$ are central cytokines in the regulatory and effector phases of the immune response to $M$ tuberculosis [6]. TH1 cells and natural killer $(\mathrm{NK})$ cells secrete IFN- $\gamma$, which activates alveolar macrophages to produce a variety of substances involved in growth inhibition and killing of mycobacteria. Macrophages also secrete IL-12, amplifying this pathway

Correspondence and reprint requests to Figen Deveci, Department of Chest Diseases, Firat Medical Center, Faculty of Medicine, Firat University, 23119 Elazig, Turkey; fdeveci@firat.edu.tr in a positive feedback loop [1]. IL-12 has been implicated in the pathogenesis of T-cell-mediated pathology because it drives antigen-naive TH cells towards development into TH1 cells [7]. TNF- $\alpha$ is believed to play multiple roles in the immune and pathological responses in tuberculosis. $M$ tuberculosis induces TNF- $\alpha$ secretion by macrophages, dendritic cells, and $\mathrm{T}$ cells [8]. The production of antiinflammatory cytokines such as IL-4, IL-10 and TGF- $\beta$ in response to $M$ tuberculosis may down-regulate the immune response and limit tissue injury, but excessive production of these cytokines may result in failure to control the infection [9].

Few researchers have studied changes in systemic cytokine levels in patients with tuberculosis and these few have obtained different results. The aim of the present study was to determine the serum concentrations of IL$12 \mathrm{p} 40, \mathrm{IL}-4, \mathrm{IL}-10$, TNF- $\alpha$, IFN- $\gamma$, and TGF- $\beta 1$ in patients with active and inactive pulmonary tuberculosis and to compare these values with (a) those obtained from normal blood donors, and (b) those obtained from the patients after therapy.

\section{MATERIAL AND METHODS}

The study population consisted of 20 newly diagnosed APTB outpatients admitted to the Firat Medical Center and Elazig Tuberculosis Dispensary (group 1; mean \pm SD 
TABLE 1. Serum levels of cytokines in active pulmonary tuberculosis (APTB) cases, inactive pulmonary tuberculosis (IPTB) cases, and healthy controls (HC).

\begin{tabular}{c|ccc}
\hline Cytokines $(\mathrm{pg} / \mathrm{mL})$ & APTB cases $(n=20)($ baseline $)$ & IPTB cases $(n=9)$ & HC $(n=9)$ \\
\hline IL-12 p40 & $10.4 \pm 6.2^{\mathrm{a}}$ & $7.3 \pm 3.2$ & $5.7 \pm 4.9^{\mathrm{a}}$ \\
IL-4 & $33.5 \pm 2.6$ & $32.4 \pm 2.2$ & $33.9 \pm 1.9$ \\
IL-10 & $5.9 \pm 1.9^{\mathrm{bc}}$ & $4.5 \pm 4.1^{\mathrm{b}}$ & $3.6 \pm 2.0^{\mathrm{c}}$ \\
TNF- $\alpha$ & $57.6 \pm 12.2^{\mathrm{de}}$ & $49.8 \pm 10.3^{\mathrm{d}}$ & $45.6 \pm 4.7^{\mathrm{e}}$ \\
IFN- $\gamma$ & $19.1 \pm 3.2^{\mathrm{fg}}$ & $14.7 \pm 2.5^{\mathrm{f}}$ & $15.8 \pm 5.3^{\mathrm{g}}$ \\
TGF- $\beta 1$ & $258.1 \pm 306.6$ & $185.1 \pm 216.5$ & $110.3 \pm 83.2$ \\
\hline
\end{tabular}

${ }^{\mathrm{a}} P=.012,{ }^{\mathrm{b}} P=.016,{ }^{\mathrm{c}} P=.011,{ }^{\mathrm{d}} P=.024,{ }^{\mathrm{e}} P=.002,{ }^{\mathrm{f}} P=.001,{ }^{\mathrm{g}} P=.003$.

age $=38.70 \pm 18.51,9$ men and 11 women). Diagnosis of tuberculosis (TB) was based on clinical and radiological data along with the identification of tubercule bacilli in sputum (at least one positive sputum smear and culture result for acid-fast bacilli). Acid-fast bacillus staining was performed by the Ziehl-Neelsen method. $M$ tuberculosis was cultured on Löwenstein-Jensen solid media. As first line therapy, a standard antituberculous regimen for nonresistant cases including INH, RMP, PZA, and EMB or SM daily for 2 months and INH, RIF daily for 4 months had been given to all the patients. Clinically they all had mild disease and underwent uneventful recovery following chemotherapy. No extrapulmonary involvement was found in any patient. Patients who had diabetes mellitus, pregnancy or immunological or autoimmune diseases other than tuberculosis were excluded from the study. None of the subjects had serological evidence of HIV infection.

Nine IPTB cases that were registered and treated in the Elazig Tuberculosis Dispensary (group 2; mean \pm SD age $35.67 \pm 18.02$, 4 men, 5 women) were also included, and 9 healthy volunteer subjects living same area were included as a control group (HC, group 3; mean \pm SD age $33.70 \pm 4.27,3$ men, 6 women). The IPTB patients had a history of previous TB episodes with a positive culture documented at the time of diagnosis. There were abnormal stable radiographical findings and no changes had been observed during the previous six months. Three sputum cultures for $M$ tuberculosis were negative in all the IPTB patients [10].

Tuberculin testing was performed by the Mantoux test: 5 IU PPD (BB-NCIPD Ltd, Sophia, Bulgaria) was injected intradermally into the volar surface of the forearm and the results were evaluated 72 hours later. A transverse induration of $\geq 10 \mathrm{~mm}$ was considered positive. All APTB and IPTB patients were positive on the PPD skin test. The healthy subjects had been vaccinated with BCG as part of the obligatory Turkey National Vaccination Program and all were tuberculin positive.

Venous blood samples $(5 \mathrm{~mL})$ were taken from all controls (baseline only) and from the APTB patients at baseline, that is, before starting antituberculosis treatment (ATT), and after 2, 4, and 6 months of ATT. The blood samples were centrifuged at $5000 \mathrm{rpm}$ for 10 minutes; sera were collected and stored at $-80^{\circ} \mathrm{C}$ until they were assayed. IL-12p40, IL-4, IL-10, TNF- $\alpha$, TGF- $\beta 1$, IFN- $\gamma$ levels were measured simultaneously in all serum samples by ELISA, following the manufacturer's instructions on a commercial kit (Medgenix, Biosource International, Camarillo, USA).

Informed consent was obtained from all subjects.

\section{Statistical analysis}

Statistical analysis was performed using SPSS 12.0 packet software. The data were expressed as arithmetic means with standard deviations; $P<.05$ was considered statistically significant. Differences in cytokine levels among groups were evaluated by the Kruskal-Wallis and Mann-Whitney $U$ tests. Differences in group 1 cytokine levels between different treatment stages were evaluated by paired-samples $t$ tests.

\section{RESULTS}

There were no statistically significant age or gender differences among the groups. The mean PPD response was statistically higher in the APTB $(14.9 \pm 2.3 \mathrm{~mm})$ and IPTB $(14.7 \pm 1.7 \mathrm{~mm})$ cases than the HC $(12.2 \pm 2.2 \mathrm{~mm})$ $(P=.011$ for APTB and $P=.025$ for IPTB compared with $\mathrm{HC})$.

The serum IL-12p40, IL-4, IL-10, TNF- $\alpha$, IFN- $\gamma$, and TGF- $\beta 1$ levels in the APTB and IPTB cases and HC are shown in Table 1.

The mean serum IL-10, TNF- $\alpha$, and IFN- $\gamma$ levels were significantly higher in the APTB than the IPTB cases $(P=$ $.016, P=.024, P=.001$, resp $)$ or the $\mathrm{HC}(P=.011, P=$ $.002, P=.003$, resp). There were no significant differences in serum IL- 4 and TGF- $\beta 1$ levels among the groups $(P>$ $.05)$. The mean serum levels of IL-12p40 were significantly higher in the APTB cases than HC $(P=.012)$ (Table 1$)$.

Figure $1 \mathrm{~b}$ shows that the mean serum IL-10 level decreased significantly in group 1 patients after antituberculous therapy (ATT) for $4(3.5 \pm 2.1 \mathrm{pg} / \mathrm{mL})$ and $6(3.5 \pm$ $1.7 \mathrm{pg} / \mathrm{mL})$ months (baseline level $5.9 \pm 1.9 \mathrm{pg} / \mathrm{mL})(P=$ $.018, P=.000$, resp). The same was true of TNF- $\alpha$ (Figure 1a); the levels after 4 and 6 months were $48.5 \pm 12.2$ 


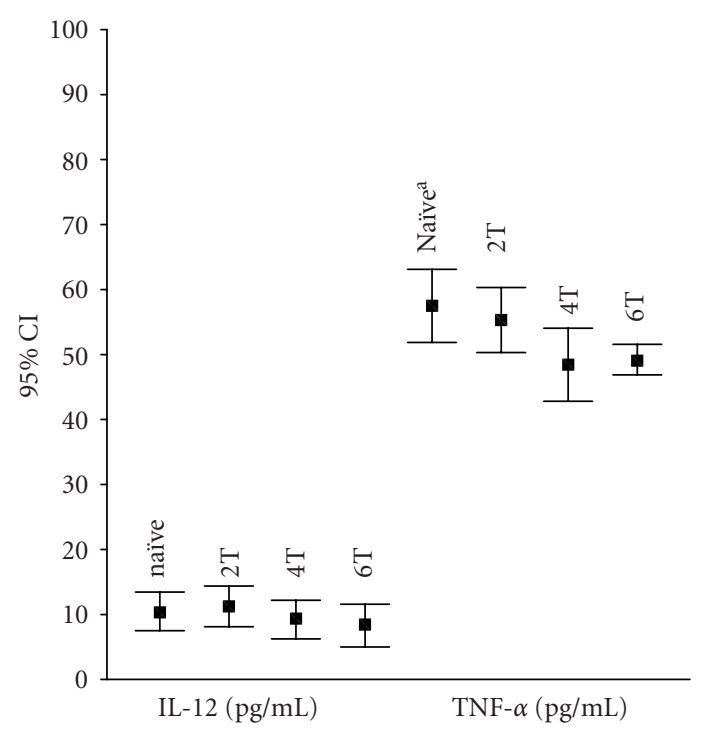

(a)

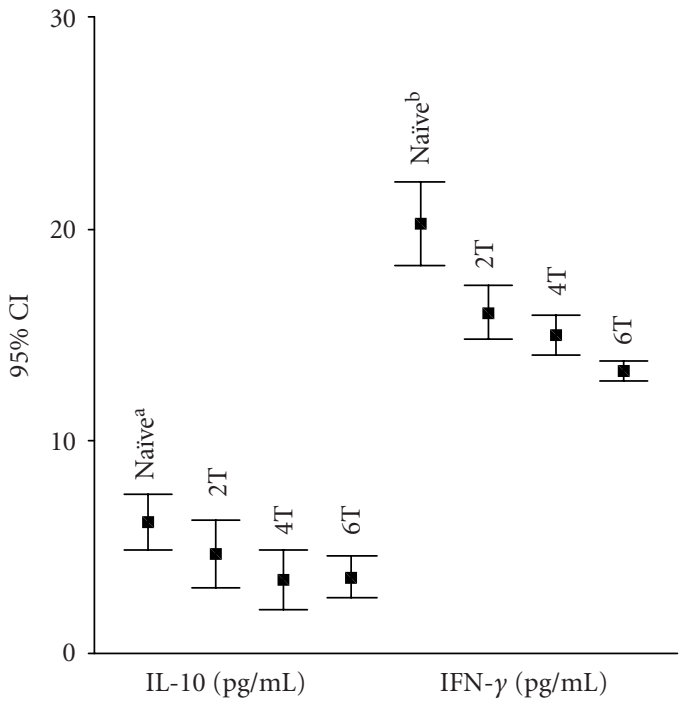

(b)

FIgURE 1. The mean serum levels of (a) IL-12 and TNF- $\alpha$ and (b) IL-10 and IFN- $\gamma$ in APTB patients $(n=20)$. Naïve: patients who had not received ATT. 2T: patients who received ATT for two months. 4T: patients who received ATT for four months. 6T: patients who received ATT for six months. ${ }^{a}$ Significantly different compared with $4 \mathrm{~T}(P=.034$ for TNF- $\alpha, P=.018$ for IL-10) and $6 \mathrm{~T}(P=.004$ for TNF- $\alpha, P=.000$ for IL-10) patients. ${ }^{\mathrm{b}}$ Significantly different compared with $2 \mathrm{~T}(P=.008), 4 \mathrm{~T}(P=.000)$, and $6 \mathrm{~T}(P=.001)$.

and $49.2 \pm 4.9 \mathrm{pg} / \mathrm{mL}$, respectively; the level before therapy was $57.6 \pm 12.2 \mathrm{pg} / \mathrm{mL}(P=.034, P=.004$, resp $)$. Also, the serum IFN- $\gamma$ levels decreased in the APTB patients after $2(16.6 \pm 1.9 \mathrm{pg} / \mathrm{mL}), 4(14.7 \pm 1.8 \mathrm{pg} / \mathrm{mL})$, and $6(14.5 \pm 3.4 \mathrm{pg} / \mathrm{mL})$ months of therapy (Figure 1b); the baseline value was $19.1 \pm 3.2 \mathrm{pg} / \mathrm{mL}(P=.008, P=.000$, $P=.001$, resp). There were no significant differences in these parameters between patients who received ATT for 6 months and $\mathrm{HC}(P>.05)$. Treatment effected no significant differences in IL- 4 and TGF- $\beta 1$ levels $(P>.05)$. The decrease in serum IL-12p40 levels during therapy was insignificant (Figure 1a).

\section{DISCUSSION}

We found significantly raised serum levels of IL-10, IL-12p40, TNF- $\alpha$, and IFN- $\gamma$ in patients with APTB. Therapy affected statistically significant decreases in the concentrations of all these cytokines except IL-12p40.

Previous studies of stimulated peripheral blood mononuclear cells (PBMNC) or $\mathrm{CD}^{+} \mathrm{T}$ cells from $\mathrm{TB}$ patients showed increased, unchanged, or decreased cytokine production $[11,12,13]$. TNF- $\alpha$ is produced at the site of disease in tuberculosis patients [14]. Early clinical deterioration in treatment is associated with a selective increase of TNF- $\alpha$ in plasma [15]. In particular, patients with PTB accompanied by systemic manifestations (persistent fever, weight loss) showed increased TNF- $\alpha$ and IL-10 and decreased IL-12 levels compared with controls [16]. IL-12, which is mediated by IL-10, has a role in host defense against $M$ tuberculosis and is essential for inducing
IFN- $\gamma$ production [17]. One study showed that the TNF$\alpha$ and IFN- $\gamma$ levels were raised in PBMNC from patients stimulated with the 30-kd antigen of $M$ tuberculosis compared to controls, but there was no difference in IL-10 levels [18]. However, no significant differences were found in the number of IFN- $\gamma$ producing lymphocytes when PBMNC from tuberculosis patients and healthy contacts were stimulated in vitro with $M$ tuberculosis antigens [19]. In patients with advanced stages of PTB, the $30-k d$ antigen of $M$ tuberculosis induces increased production of IL-10 and decreased production of IFN- $\gamma$ by PBMNC [20]. Increased levels of IL-10 and TGF- $\beta$ have been reported in sera from TB patients, and in vitro IL- 10 and TGF- $\beta$ secretion by the PBMNC and/or monocytes is increased in TB patients in response to $M$ tuberculosis antigens [21]. In the study by Lee et al, there was no statistically significant difference in IL-12p40 production between newly diagnosed pulmonary TB and healthy tuberculin reactors (HTR) after in vitro stimulation with antigens [22]. Several studies have described altered IL-12 after $M$ tuberculosis infection in TB patients at various clinical stages. The IL-12 level is relatively high in patients with advanced pulmonary $\mathrm{TB}$ who produce low levels of IFN- $\gamma$ compared to moderate cases or HTRs [23]. A greater increase in IL-12 was seen in $\mathrm{TB}$ patients than in healthy donors in peripheral blood stimulated by mycobacteria [24].

Differences among reports of systemic cytokine balance in TB patients based on in vitro stimulation studies might be attributable to differences in isolation and culture techniques, or in the stimulus used, and may not reflect the actual situation in vivo $[25,26]$. Previous studies 
have shown higher serum levels of TNF- $\alpha$ in pulmonary TB patients than control subjects $[27,28,29,30]$. Also, serum TNF- $\alpha$ levels were significantly higher in both active and inactive TB patients than healthy controls, and significantly higher in active than inactive $\mathrm{TB}$ patients [31]. Furthermore, increased TNF- $\alpha$ has been reported in early stages of $\mathrm{TB}$, and this extends to plasma from contacts of pulmonary TB patients who are suspected of being in early stages of $\mathrm{TB}$ infection but are not $\mathrm{TB}$ patients [32]. Our results agree with above reports in that serum TNF- $\alpha$ levels are elevated in APTB patients compared to IPTB patients and controls.

The study by Dlugovitzky et al demonstrated that the serum levels of IFN- $\gamma$ were increased in patients with $\mathrm{PTB}$, especially in mild and moderate TB cases compared to advanced TB [26]. There is in vitro evidence that $\mathrm{TB}$ patients with progressive disease fail to generate IFN- $\gamma$ in response to stimulation with mycobacterial antigens $[33,34]$. Other studies that evaluated serum IFN- $\gamma$ levels in TB patients showed increases relative to control subjects $[28,35,36]$. According to our results and others, IFN- $\gamma$ is an important cytokine in TH1mediated cellular immunity. T lymphocyte activation following mycobacterial antigen recognition on antigen presenting cells induces a variety of responses in CD4+ TĤ1 cells, including cytotoxic activity against infected macrophages and synthesis of IFN- $\gamma$. In turn, IFN- $\gamma$ stimulates human macrophages to produce TNF- $\alpha$ and 1,25dihydroxyvitamin $\mathrm{D}$, both of which facilitate mycobacterial inhibition [37, 38, 39].

Mycobacterial products induce the production of TGF- $\beta$ by monocytes and dendritic cells; TGF- $\beta$ is produced in excess during TB and is expressed at the site of disease [40, 41]. It suppresses cell-mediated immunity; in $\mathrm{T}$ cells, it inhibits proliferation, IFN- $\gamma$ production, and proinflammatory cytokine production, and it is known to counteract TNF- $\alpha$ production by monocytes $[42,43]$. One study of in vitro stimulation of PBMN showed higher TGF- $\beta$, IFN- $\gamma$, and TNF- $\alpha$ levels in samples from TB patients than control subjects [23]. In addition, Fiorenza et al [44] found increased levels of both TGF- $\beta$ and TNF$\alpha$ in severe TB patients. While having some antiinflammatory effects, excessive TGF- $\beta$ in severe disease may also have harmful consequences for host resistance because it counteracts productive immune mechanisms against $\mathrm{TB}$ [39]. In our study no differences in the serum TGF- $\beta 1$ levels were found between APTB patients on one hand and IPTB patients or controls on the other, although there was a significantly increased level of TNF- $\alpha$ in the APTB patients. These results suggest that TGF- $\beta 1$ has proinflammatory activity at low concentrations and antiinflammatory activities at high concentrations. Similar results were obtained by Olobo et al [32], who found significantly elevated plasma levels of TGF- $\beta$ but undetectable plasma levels of TNF- $\alpha$ in TB patients. According to their interpretation, the undetectable plasma levels of TNF- $\alpha$ may be due to the purported suppressive effect of TGF- $\beta$. Overall, the interactions of TNF- $\alpha$ and TGF- $\beta$ are complex and further studies are needed; cytokine responsiveness and expression may be influenced by cell type and context.

We found no significant differences among groups in the serum levels of IL-4. TH 2 responses and IL-4 in TB are subjects of some controversy. Some previous studies have shown increased production of IL-4 in human TB patients, especially those with cavitary disease $[19,45]$; according to others, it still remains to be determined whether IL-4 causes or merely reflects disease activity in human TB $[12,46]$. Some studies showed no detectable IL-4 in any TB patient and no significant difference in IL-4 level between TB patients and controls [11, 25, 41, 47, 48]. Increased levels of IL-10 have been found in TB patients $[25,49,50]$. As expected, we found raised serum levels of IL-10 in APTB compared to other groups. Studies evaluating the number of peripheral IL-12 producing cells, as well as cytokine expression in lymph nodes or BAL, showed elevated IL-12 production in TB patients $[24,51]$. In contrast, one study [35] showed no difference in serum IL-12 levels between TB patients and controls. Verbon et al [25] demonstrated that serum IL-12p40 levels were not significantly different between active TB and control groups, and were significantly lower in patients with than those without a positive. In the present study, we found that APTB patients had higher serum IL-12p40 than control subjects. We think that IL-12p40 plays a role in antimicrobial host defence. These reports suggest that an altered balance between cytokines is implicated in TB disease, rather than elevation or decrease of just one cytokine [25].

We aimed to evaluate serum cytokine levels in APTB patients before and after therapy. Statistically significant reductions were found in both IL-10 and TNF- $\alpha$ levels following 4 months of therapy, and in IFN- $\gamma$ levels following 2 months of therapy, but no change in IL-12, IL-4, or TGF- $\beta 1$ levels. One study, which evaluated serum levels of pro or antiinflammatory cytokines before and after treatment in pulmonary TB patients, showed that IFN$\gamma$ and TNF- $\alpha$ levels in BAL were decreased, IL-4 levels were increased, and serum levels of IFN- $\gamma$, TNF- $\alpha$, and TGF- $\beta 1$ were decreased [28]. Similarly, Tang et al [31] and Kawaguchi et al [30] found decreased TNF- $\alpha$ levels and Berktas et al [36] found decreased IFN- $\gamma$ levels in TB patients after therapy. The increased plasma TNF- $\alpha$ level may be associated with the clinical deterioration observed early in treatment of severe TB [15]. In a recent study, TNF- $\alpha$ levels in sputum decreased following initiation of ATT but serum TNF- $\alpha$ levels were unchanged after 12 weeks [52]. Kart et al [27] found that the increased TNF- $\alpha$ levels were not changed after ATT and suggested that TNF- $\alpha$ may be involved in delayed-type hypersensitivity responses, although the levels were not correlated with sequela and cavity formation in their cases and the systemic cytokine responses were different from the local response to ATT. We believe that evaluating the serum cytokine levels may be useful in evaluating the clinical effect of antituberculous therapy. 
In conclusion, proinflammatory cytokines play an especially important role in the pathogenesis of active pulmonary tuberculosis. We show here that only one antiinflammatory cytokine (IL-10) is elevated in the serum of APTB patients. Measuring the serum levels of several cytokines may be useful for evaluating the activity of TB disease and monitoring the clinical effect of antituberculous treatment. Further studies are needed to address the role of cytokines in immunity to TB under natural conditions.

\section{REFERENCES}

[1] Schluger NW, Rom WN. The host immune response to tuberculosis. Am J Respir Crit Care Med. 1998;157(3 pt 1):679-691.

[2] Raviglione MC, Snider DE Jr, Kochi A. Global epidemiology of tuberculosis. Morbidity and mortality of a worldwide epidemic. JAMA. 1995;273(3):220226.

[3] World Health Organization. Making a Difference.Geneva, Switzerland: World Health Organization; 1999. The World Health Report. p. 110.

[4] Hamzaoglu O, Kiliç B. Türkiye Saglik Istatistikleri. Ankara, Turkey: Türk Tabipleri Birligi; 2000.

[5] Munk ME, Emoto M. Functions of T-cell subsets and cytokines in mycobacterial infections. Eur Respir J Suppl. 1995;20:668-675.

[6] Boom WH, Canaday DH, Fulton SA, Gehring AJ, Rojas RE, Torres M. Human immunity to M. tuberculosis: T cell subsets and antigen processing. Tuberculosis (Edinb). 2003;83(1-3):98-106.

[7] Trinchieri G. Interleukin-12: a cytokine produced by antigen-presenting cells with immunoregulatory functions in the generation of T-helper cells type 1 and cytotoxic lymphocytes. Blood. 1994;84(12): 4008-4027.

[8] Raja A. Immunology of tuberculosis. Indian J Med Res. 2004;120(4):213-232.

[9] Sharma S, Bose M. Role of cytokines in immune response to pulmonary tuberculosis. Asian Pac J Allergy Immunol. 2001;19(3):213-219.

[10] American Thoracic Society. Diagnostic standards and classification of tuberculosis. Am Rev Respir Dis. 1990;142(3):725-735.

[11] Zhang M, Lin Y, Iyer DV, Gong J, Abrams JS, Barnes PF. T-cell cytokine responses in human infection with mycobacterium tuberculosis. Infect Immun. 1995;63(8):3231-3234.

[12] Lai CK, Ho S, Chan CH, et al. Cytokine gene expression profile of circulating CD4 + T cells in active pulmonary tuberculosis. Chest. 1997;111(3):606-611.

[13] Bonecini-Almeida MG, Ho JL, Boechat $\mathrm{N}$, et al. Down-modulation of lung immune responses by interleukin-10 and transforming growth factor beta (TGF-beta) and analysis of TGF-beta receptors I and II in active tuberculosis. Infect Immun. 2004;72(5):2628-2634.
[14] Barnes PF, Lu S, Abrams JS, Wang E, Yamamura M, Modlin RL. Cytokine production at the site of disease in human tuberculosis. Infect Immun. 1993;61(3):3482-3489.

[15] Bekker LG, Maartens G, Steyn L, Kaplan G. Selective increase in plasma tumor necrosis factor-alpha and concomitant clinical deterioration after initiating therapy in patients with severe tuberculosis. J Infect Dis. 1998;178(2):580-584.

[16] Pereira CB, Palaci M, Leite OH, Duarte AJ, Benard G. Monocyte cytokine secretion in patients with pulmonary tuberculosis differs from that of healthy infected subjects and correlates with clinical manifestations. Microbes Infect. 2004;6(1):25-33.

[17] O’Neill LA, Greene C. Signal transduction pathways activated by the IL-1 receptor family: ancient signaling machinery in mammals, insects, and plants. J Leukoc Biol. 1998;63(6):650-657.

[18] Portales-Perez DP, Baranda L, Layseca E, et al. Comparative and prospective study of different immune parameters in healthy subjects at risk for tuberculosis and in tuberculosis patients. Clin Diagn Lab Immunol. 2002;9(2):299-307.

[19] Surcel HM, Troye-Blomberg M, Paulie S, et al. Th1/Th2 profiles in tuberculosis, based on the proliferation and cytokine response of blood lymphocytes to mycobacterial antigens. Immunology. 1994;81(2):171-176.

[20] Torres M, Herrera T, Villareal H, Rich EA, Sada E. Cytokine profiles for peripheral blood lymphocytes from patients with active pulmonary tuberculosis and healthy household contacts in response to the 30-kilodalton antigen of mycobacterium tuberculosis. Infect Immun. 1998;66(1):176-180.

[21] Hirsch CS, Ellner JJ, Blinkhorn R, Toossi Z. In vitro restoration of $\mathrm{T}$ cell responses in tuberculosis and augmentation of monocyte effector function against mycobacterium tuberculosis by natural inhibitors of transforming growth factor beta. Proc Natl Acad Sci USA. 1997;94(8):3926-3931.

[22] Lee JS, Song CH, Kim CH, et al. Depressed interleukin-12 production by peripheral blood mononuclear cells after in vitro stimulation with the $30 \mathrm{kDa}$ antigen in recurrent pulmonary tuberculosis patients. Med Microbiol Immunol (Berl). 2003;192(2):61-69.

[23] Dlugovitzky D, Bay ML, Rateni L, et al. Influence of disease severity on nitrite and cytokine production by peripheral blood mononuclear cells (PBMC) from patients with pulmonary tuberculosis (TB). Clin Exp Immunol. 2000;122(3):343-349.

[24] Munk ME, Mayer P, Anding P, Feldmann K, Kaufmann SH. Increased numbers of interleukin-12producing cells in human tuberculosis. Infect Immun. 1996;64(3):1078-1080.

[25] Verbon A, Juffermans N, Van Deventer SJ, Speelman P, Van Deutekom H, Van Der Poll T. Serum 
concentrations of cytokines in patients with active tuberculosis (TB) and after treatment. Clin Exp Immunol. 1999;115(1):110-113.

[26] Dlugovitzky D, Torres-Morales A, Rateni L, et al. Circulating profile of Th1 and Th2 cytokines in tuberculosis patients with different degrees of pulmonary involvement. FEMS Immunol Med Microbiol. 1997;18(3):203-207.

[27] Kart L, Buyukoglan H, Tekin IO, et al. Correlation of serum tumor necrosis factor-alpha, interleukin-4 and soluble interleukin-2 receptor levels with radiologic and clinical manifestations in active pulmonary tuberculosis. Mediators Inflamm. 2003;12(1):9-14.

[28] Ameglio F, Casarini M, Capoluongo E, Mattia P, Puglisi G, Giosue S. Post-treatment changes of six cytokines in active pulmonary tuberculosis: differences between patients with stable or increased fibrosis. Int J Tuberc Lung Dis. 2005;9(1):98-104.

[29] Nakaya M, Yoneda T, Yoshikawa M, et al. The evaluation of interleukin-8 (IL-8) and tumor necrosis factor-alpha (TNF-alpha) level in peripheral blood of patients with active pulmonary tuberculosis. Kekkaku. 1995;70(8):461-466.

[30] Kawaguchi H, Ina Y, Ito S, et al. Serum levels of solubule tumor necrosis factor (TNF) receptors in patients with pulmonary tuberculosis. Kekkaku. 1996;71(3):259-265.

[31] Tang S, Xiao H, Fan Y, et al. Changes of proinflammatory cytokines and their receptors in serum from patients with pulmonary tuberculosis. Zhonghua Jie He He Hu Xi Za Zhi. 2002;25(6):325-329.

[32] Olobo JO, Geletu M, Demissie A, et al. Circulating TNF-alpha, TGF-beta, and IL-10 in tuberculosis patients and healthy contacts. Scand J Immunol. 2001;53(1):85-91.

[33] Huygen K, Van Vooren JP, Turneer M, Bosmans R, Dierckx P, De Bruyn J. Specific lymphoproliferation, gamma interferon production, and serum immunoglobulin $\mathrm{G}$ directed against a purified $32 \mathrm{kDa}$ mycobacterial protein antigen (P32) in patients with active tuberculosis. Scand J Immunol. 1988;27(2):187-194.

[34] Vilcek J, Klion A, Henriksen-DeStefano D, et al. Defective gamma-interferon production in peripheral blood leukocytes of patients with acute tuberculosis. J Clin Immunol. 1986;6(2):146-151.

[35] Morosini M, Meloni F, Marone Bianco A, et al. The assessment of IFN-gamma and its regulatory cytokines in the plasma and bronchoalveolar lavage fluid of patients with active pulmonary tuberculosis. Int J Tuberc Lung Dis. 2003;7(10):994-1000.

[36] Berktas M, Guducuoglu H, Bozkurt H, Onbasi KT, Kurtoglu MG, Andic S. Change in serum concentrations of interleukin-2 and interferon-gamma during treatment of tuberculosis. J Int Med Res. 2004;32(3):324-330.

[37] Bermudez LE, Young LS. Tumor necrosis factor, alone or in combination with IL-2, but not
IFN-gamma, is associated with macrophage killing of mycobacterium avium complex. J Immunol. 1988;140(9):3006-3013.

[38] Rook GA, Steele J, Fraher L, et al. Vitamin D3, gamma interferon, and control of proliferation of mycobacterium tuberculosis by human monocytes. Immunology. 1986;57(1):159-163.

[39] Denis M. Killing of mycobacterium tuberculosis within human monocytes: activation by cytokines and calcitriol. Clin Exp Immunol. 1991;84(2):200206.

[40] Toossi Z, Gogate P, Shiratsuchi H, Young T, Ellner JJ. Enhanced production of TGF-beta by blood monocytes from patients with active tuberculosis and presence of TGF-beta in tuberculous granulomatous lung lesions. J Immunol. 1995;154(1):465473.

[41] Condos R, Rom WN, Liu YM, Schluger NW. Local immune responses correlate with presentation and outcome in tuberculosis. Am J Respir Crit Care Med. 1998;157(3 pt 1):729-735.

[42] Toossi Z, Ellner JJ. The role of TGF beta in the pathogenesis of human tuberculosis. Clin Immunol Immunopathol. 1998;87(2):107-114.

[43] Bogdan C, Paik J, Vodovotz Y, Nathan C. Contrasting mechanisms for suppression of macrophage cytokine release by transforming growth factorbeta and interleukin-10. J Biol Chem. 1992;267(32): 23301-23308.

[44] Fiorenza G, Rateni L, Farroni MA, Bogue C, Dlugovitzky DG. TNF-alpha, TGF-beta and no relationship in sera from tuberculosis (TB) patients of different severity. Immunol Lett. 2005;98(1):45-48.

[45] van Crevel R, Karyadi E, Preyers F, et al. Increased production of interleukin 4 by CD4+ and CD8+ $\mathrm{T}$ cells from patients with tuberculosis is related to the presence of pulmonary cavities. J Infect Dis. 2000;181(3):1194-1197.

[46] Lin Y, Zhang M, Hofman FM, Gong J, Barnes PF. Absence of a prominent Th2 cytokine response in human tuberculosis. Infect Immun. 1996;64(4):1351-1356.

[47] Zhong D, Dong L, Liang Q. Alteration of interferongamma and interleukin-12 released by bronchoalveolar lavage cells from pulmonary tuberculosis. Zhonghua Jie He He Hu Xi Za Zhi. 2000;23(9):552555.

[48] Sanchez FO, Rodriguez JI, Agudelo G, Garcia LF. Immune responsiveness and lymphokine production in patients with tuberculosis and healthy controls. Infect Immun. 1994;62(12):5673-5678.

[49] Yamamura M, Uyemura K, Deans RJ, et al. Defining protective responses to pathogens: cytokine profiles in leprosy lesions. Science. 1991;254(5029):277-279.

[50] Barnes PF, Chatterjee D, Abrams JS, et al. Cytokine production induced by mycobacterium tuberculosis lipoarabinomannan. Relationship to chemical structure. J Immunol. 1992;149(2):541-547. 
[51] Taha RA, Kotsimbos TC, Song YL, Menzies D, Hamid Q. IFN-gamma and IL-12 are increased in active compared with inactive tuberculosis. Am J Respir Crit Care Med. 1997;155(3):1135-1139.

[52] Ribeiro-Rodrigues R, Resende Co T, Johnson JL, et al. Sputum cytokine levels in patients with pulmonary tuberculosis as early markers of mycobacterial clearance. Clin Diagn Lab Immunol. 2002;9(4):818-823. 


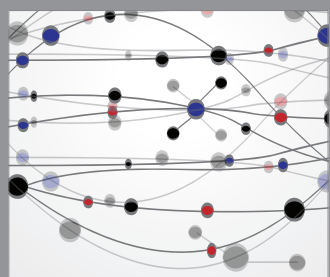

The Scientific World Journal
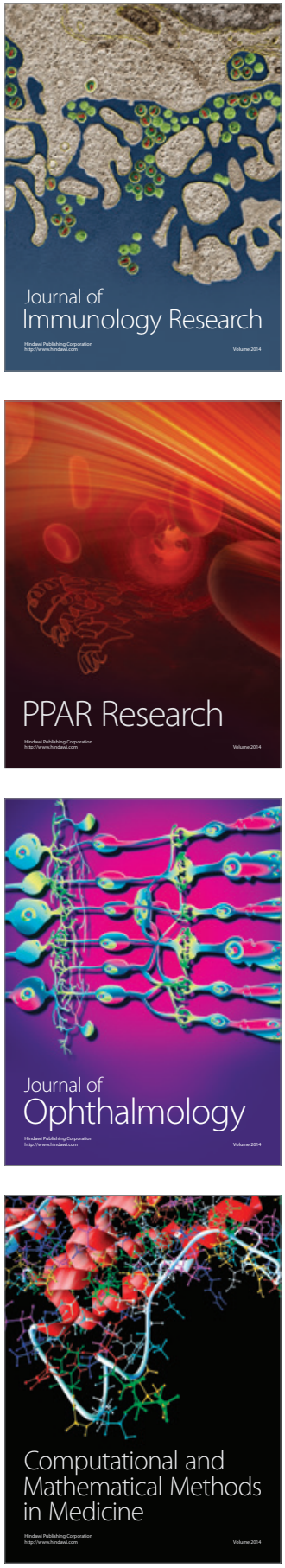

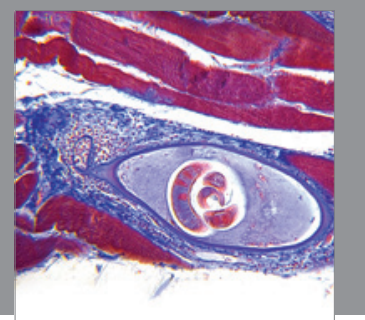

Gastroenterology

Research and Practice
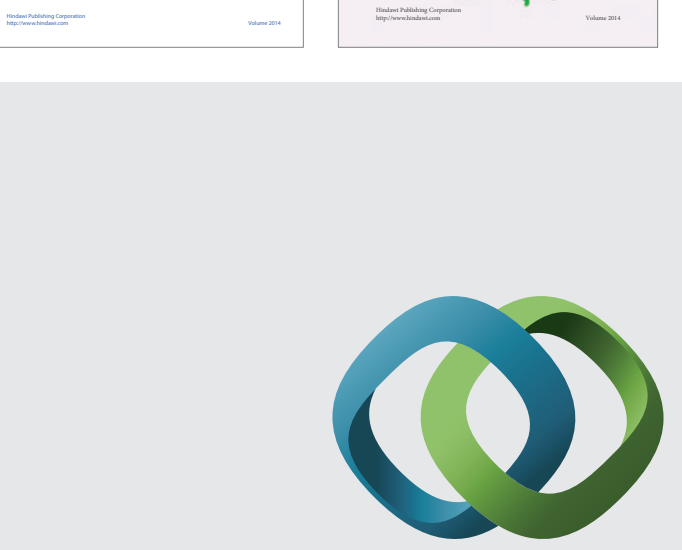

\section{Hindawi}

Submit your manuscripts at

http://www.hindawi.com
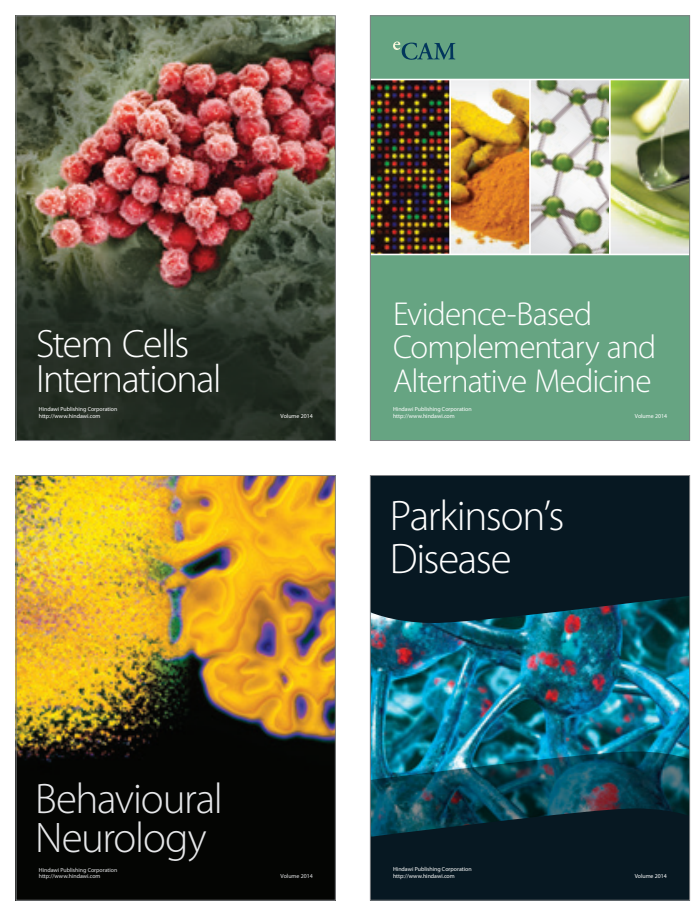

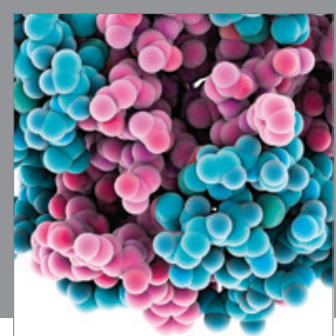

Journal of
Diabetes Research

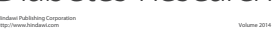

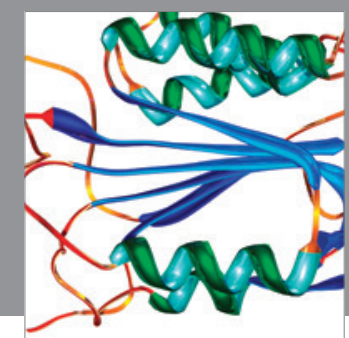

Disease Markers
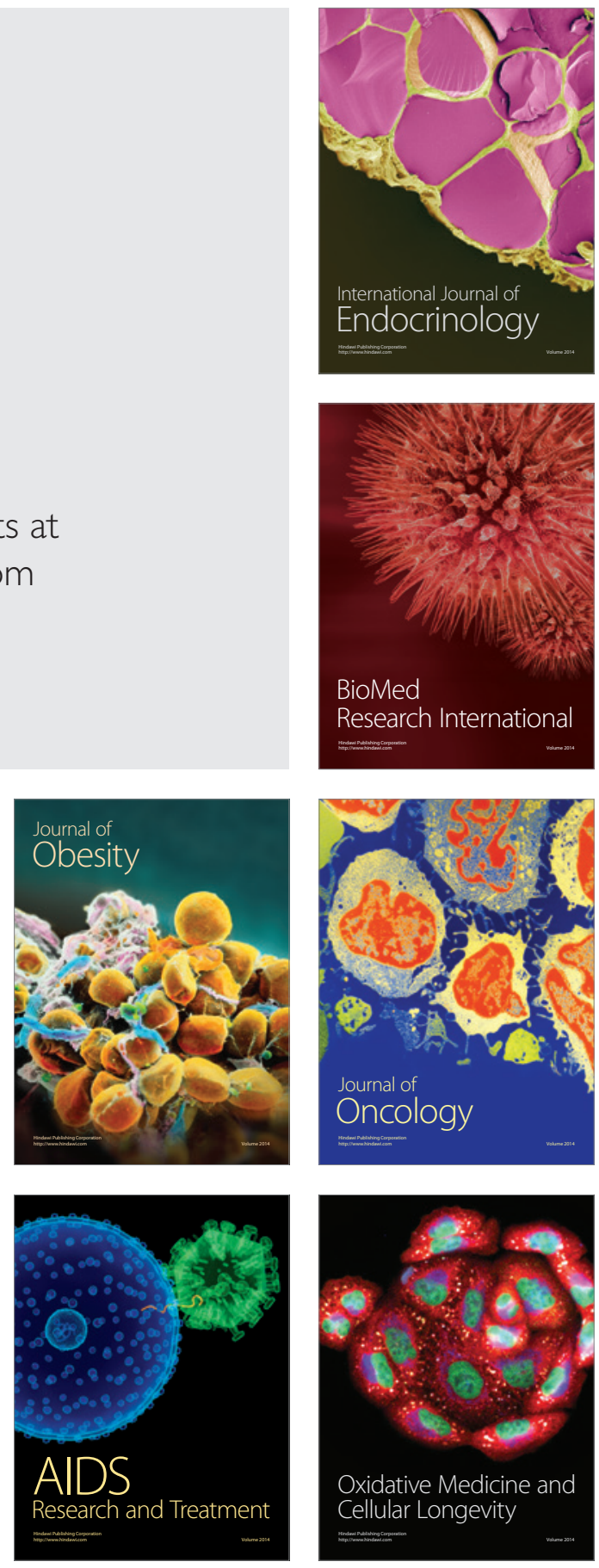